\title{
Correction to: Accumulation
} and monocytes/macrophages in pretreatment ovarian cancer patients is associated with soluble PD-L1

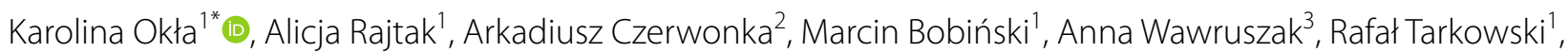
Wiesława Bednarek', Justyna Szumiło ${ }^{4}$ and Jan Kotarski ${ }^{1}$

\section{Correction to: J Transl Med (2020) 18:220}

https://doi.org/10.1186/s12967-020-02389-7

Following the publication of the original article [1], it was noted that due to a typesetting error, the Fig. 1 was replaced by a duplicate of Fig. 3. The correct Fig. 1 is given below, and the original article has been corrected. 


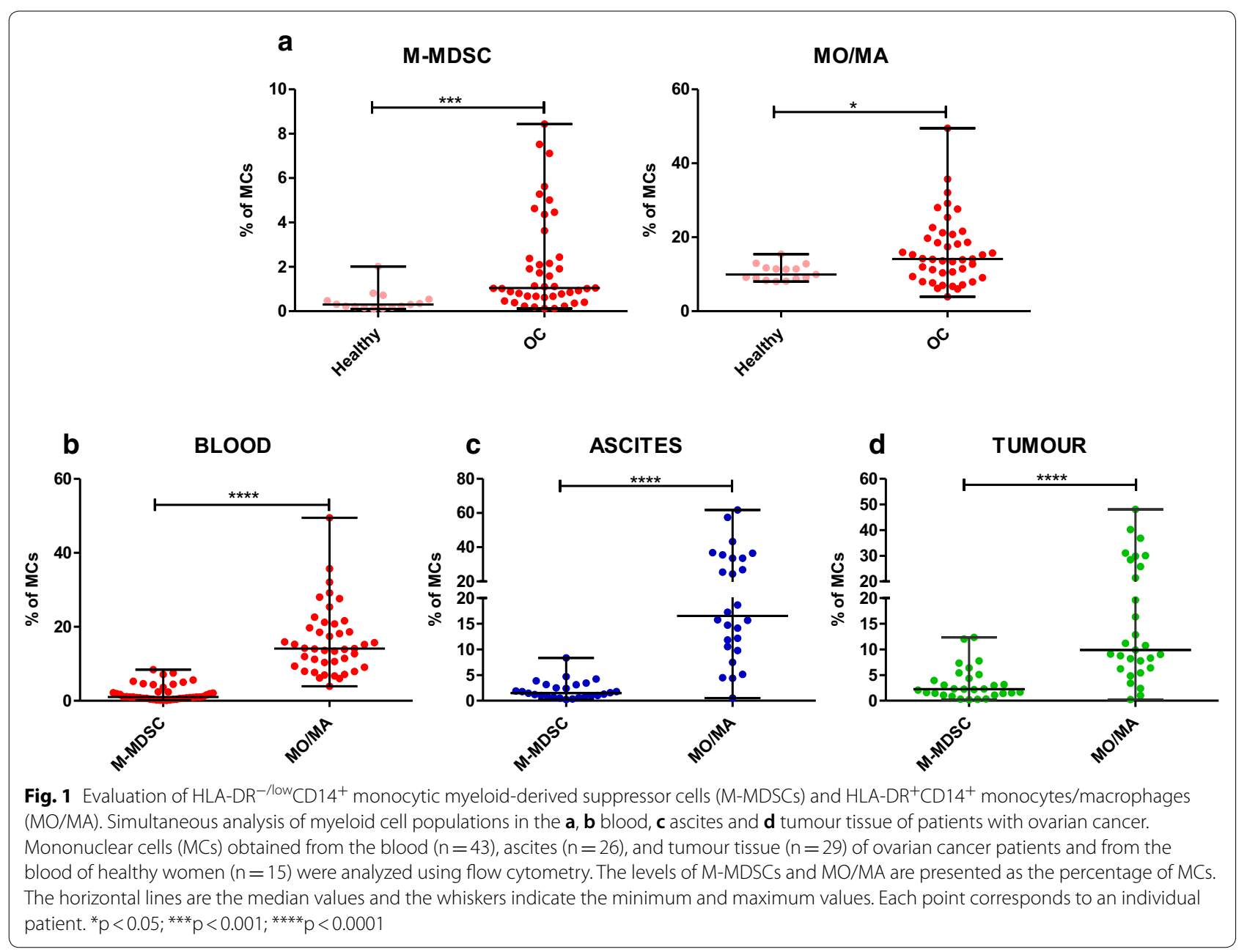

\section{Author details}

${ }^{1}$ The First Department of Oncologic Gynecology and Gynecology, Medical University of Lublin, 20-081 Lublin, Poland. ${ }^{2}$ Department of Virology and Immunology, Maria Curie-Sklodowska University, 20-031, Lublin, Poland. ${ }^{3}$ Department of Biochemistry and Molecular Biology, Medical University of Lublin, 20-081 Lublin, Poland. ${ }^{4}$ Department of Clinical Pathomorphology, Medical University of Lublin, 20-090 Lublin, Poland.

Published online: 25 June 2020

\section{Publisher's Note}

Springer Nature remains neutral with regard to jurisdictional claims in published maps and institutional affiliations.

\section{Reference}

1. Okła K, Rajtak A, Czerwonka A, Bobiński M, Wawruszak A, Tarkowski R, Bednarek W, Szumiło J, Kotarski J. Accumulation of blood-circulating PDL1-expressing M-MDSCs and monocytes/macrophages in pretreatment ovarian cancer patients is associated with soluble PD-L1. J Transl Med. 2020;18:220. https://doi.org/10.1186/s12967-020-02389-7. 